\title{
EVALUATION OF MECHANICAL AND WATER ABSORPTION BEHAVIOUR OF COIR AND RICE HUSK REINFORCED COMPOSITES
}

\author{
Abhishek T.H.M. ${ }^{1}$, G.K.Mrutyunjaya Gouda ${ }^{2}$ \\ ${ }^{l}$ M.Tech, Department of Industrial and production Engg., U.B.D.T.C.E., Davangere, India. \\ ${ }^{2} \mathrm{HOD}$, Department of Mechanical Engg., Impact College of Engineering and Applied Science,Bengaluru, India.
}

\begin{abstract}
Coconut coir and rice husk are abundantly available in nature with the very low cost, and rice husk is an agricultural waste, which is thrown away by the industry. The development of natural fiber composites from coconut coir and rice husk powder will reduce agriculture waste and increases its usable value. Composite specimens were prepared according to the ASTM standards with three different weight fractions of fiber, filler, and epoxy (5:15:80, 10:10:80, and 15:5:80) and conducted some mechanical tests such as impact test and hardness test and water absorption behaviour. From the results it was found that, the mechanical properties of untreated coir fiber and rice husk powder composites are more as compared to treated coir fiber and rice husk powder composites, but in the case of water absorption property.
\end{abstract}

Keywords: Rice Husk, Coconut Coir, Natural Composites, Epoxy Composites, Mechanical Properties, Water Absorption Behaviour.

\section{INTRODUCTION}

A composite material is a structural material whichconsists of two or more constituents that are combined at a macroscopic level and are not soluble in each other. One constituent is called the reinforcing phase and the one in which it is embedded is called the matrix. The reinforcing phase may be in the form of fibers, particles, or flakes. The matrix phase materials are generally continuous [2].

The interest in natural fiber-reinforced polymer composite materials is rapidly growing both in terms of their industrial applications and fundamental research [6]. Because natural fibers have more advantages than the synthetic fibers. Currently, many types of natural fibers have been investigated for use in plastics including jute,wood, ricehusk, coconut coir, hemp, grass, pineapple leaf fiber jute straw, wood, rice husk, sugar cane, sisal, , and banana fiber. They are environment friendly, biodegradable, extravagantly available, renewable and economical and have low density [4].

In the present study chopped coir fiber and rice husk powder are reinforced with epoxy resin for different weight fractions to prepare the composites. The specimens are prepared according to the ASTM standards to test the mechanical properties such as impact and hardness, and moisture absorption properties of the prepared composites. The effect of chemical treatment on the mechanical behaviour and moisture absorption of the composites are observed.

Advantages of natural fiber composites are

- High electrical resistance

- Good thermal and acoustic insulating properties.

- Low specific weight compared with glass fiber reinforced composites.
- Renewable resources with production requiring low $\mathrm{CO}_{2}$ emissions.

- The processing environment is worker friendly with better working conditions.

- Good thermal and acoustic insulating properties.

- Biodegradability [2].

\section{MATERIALS AND EXPERIMENTS}

\subsection{Coir Fiber}

A natural fiber such as coir fiber is abundantly available and has widespread applications in the industries. Coconut Coir is located between the husk and the outer shell of the coconut [8].Nowadays coconut coir iswidely used in many industrial applications because of its durability hard wearing quality, biodegradability and other advantages [12].The density of the coir is $1.2 \mathrm{~g} / \mathrm{cm}^{3}$ [9]. Below table summarizes the chemical composition of coir fiber [12].

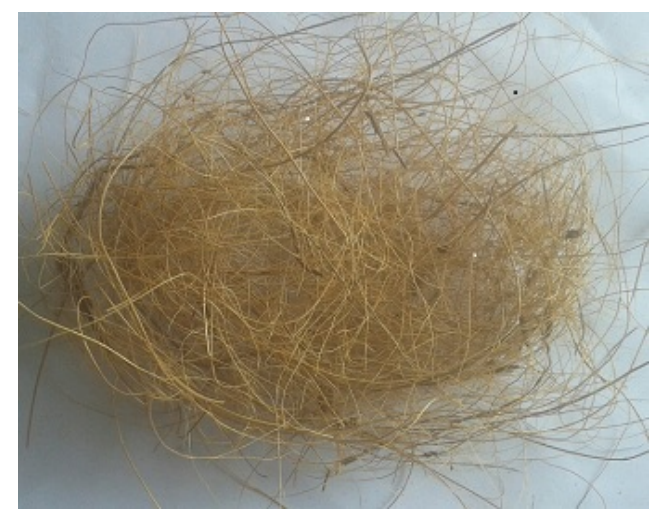

Fig -1: Coir fiber 
Table 1. Chemical composition of coir

\begin{tabular}{|l|l|}
\hline Composition & Weight in \% \\
\hline Cellulose & $32-43$ \\
\hline Hemicellulose & $0.15-0.25$ \\
\hline Lignin & $40-45$ \\
\hline Waxes & - \\
\hline
\end{tabular}

\subsection{Rice Husk}

Rice husk is the hard protecting coverings of the grains of rice. It is one of the natural materials which are widely available in India. It can be used as building material, fuel, insulation material or fertilizer. The density of the rice husk is $0.33-038 \mathrm{~g} / \mathrm{cm} 3$ [14]. Chemical composition of rice husk is shown in the below table [2].

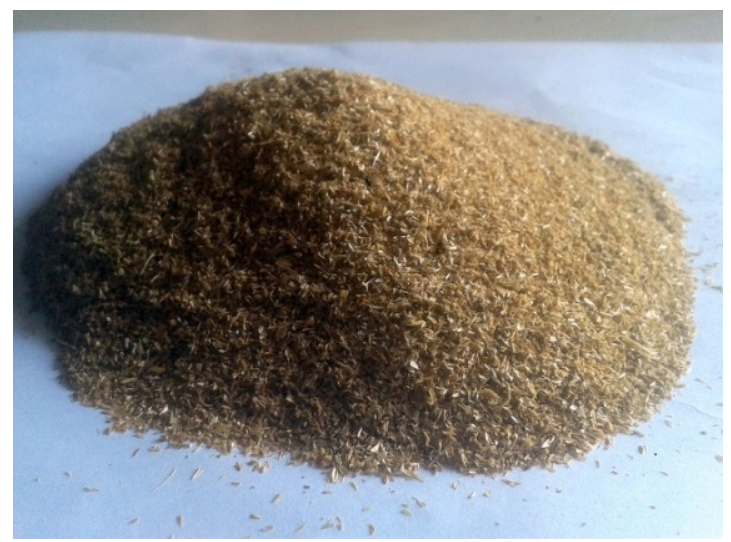

Fig -2: Rice Husk

Table 2. Chemical composition of rice husk

\begin{tabular}{|l|l|}
\hline Composition & Weight in \% \\
\hline Cellulose & $35-45$ \\
\hline Hemicellulose & $19-25$ \\
\hline Lignin & 20 \\
\hline Waxes & $14-17$ \\
\hline
\end{tabular}

\subsection{Epoxy Resin}

Epoxy resin (ER) is one of the thermosetting polymers which is widely used as matrix for fiber-reinforced composites and as structural adhesive. Epoxy system consists of two parts, resin and hardener. When it is mixed together, the resin and hardener gets activated causing a chemical reaction, which cures the material [1]. It is also good solvent and has good chemical resistance over a wide range of temperature. It has excellent adhesion Atul Ltd. Lapox L-12 and hardener K-6 is purchased from Yuje marketing, Bengaluru, India is used in the present work. Epoxy matrix, as a class of properties, has the following.

\section{CHEMICAL TREATMENT OF COIR FIBER}

For the chemical treatment of fiber, initially coir fibers are cut to the size of 5 to $10 \mathrm{~mm}$. Then the fibers are cleaned in the running water and dried. Then fibers are soaked in the $5 \% \mathrm{NaOH}$ solution for 24 hours. After that fibers are washed thoroughly with distilled water and dried at the room temperature.

\section{MOISTURE ABSORPTION TEST}

Moisture absorption studied on untreated and treated coir fiber and rice husk powder reinforced epoxy composites were carried out in various sources of water such as Distilled water,bore water and River water. The composites were immersed in the beakers containing different kinds of water. After that for every $24 \mathrm{~h}$ composites were taken out from the beakers and dried in between the folds of filter paper. Then the weight of the each composite was taken and percentage of water absorption is calculated as follows:

Percentage of water absorption $=\frac{\text { Difference in weight }}{\text { Initial wei }} \times 100$

Then the sample was again soaked in water, and this process was repeated after every $24 \mathrm{~h}$ for $264 \mathrm{~h}$ (11 days). A graph is plotted between $\%$ water absorption and number of days.

\section{METHOD OF SPECIMEN PREPERATION}

Specimens were prepared according to the ASTM standards by using the proper mould with the required specification. The inner surface of the mould was initially coated with a releasing agent to prevent the sticking of composites to the mould wall. Rice husk powder and chopped coir were mixed with epoxy and hardener in the container and stirred well for 3-5 minutes. The prepared mixture was poured in to mould and kept for curing for duration of 24 hours. After that finally specimens were cut in accordance with ASTM standards.

Table 3Details of specimen composition used and their weight proportions

\begin{tabular}{|l|l|l|l|}
\hline \multirow{2}{*}{$\begin{array}{l}\text { Specimen } \\
\text { code }\end{array}$} & $\begin{array}{l}\mid \text { Specimen composition } \\
\text { resin }\end{array}$ & $\begin{array}{l}\text { Coir fiber } \\
\text { (chopped) }\end{array}$ & $\begin{array}{l}\text { Rice } \\
\text { powder } \\
(300-600 \\
\text { microns) }\end{array}$ \\
\hline Un-treated coir fiber \\
\hline $\begin{array}{l}\text { Untreated } \\
\text { C05\%R15\% }\end{array}$ & $80 \%$ & $05 \%$ & $15 \%$ \\
\hline $\begin{array}{l}\text { Untreated } \\
\text { C10\%R10\% }\end{array}$ & $80 \%$ & $10 \%$ & $10 \%$ \\
\hline $\begin{array}{l}\text { Untreated } \\
\text { C15\%R05\% }\end{array}$ & $80 \%$ & $15 \%$ & $05 \%$ \\
\hline NaOH Treated Coir fiber & \\
\hline $\begin{array}{l}\text { Treated } \\
\text { C05\% R15\% }\end{array}$ & $80 \%$ & $05 \%$ & $15 \%$ \\
\hline $\begin{array}{l}\text { Treated } \\
\text { C10\% R10\% }\end{array}$ & $80 \%$ & $10 \%$ & $10 \%$ \\
\hline $\begin{array}{l}\text { Treated } \\
\text { C15\% R05\% }\end{array}$ & $80 \%$ & $15 \%$ & $05 \%$ \\
\hline
\end{tabular}

Where,

C05 R 15 - coir $5 \%$ and rice husk $15 \%$

C10 R10- coir $10 \%$ and rice husk $10 \%$

C15 R05- coir $15 \%$ and rice husk $05 \%$ 


\section{TESTS CONDUCTED}

\subsection{Mechanical Tests}

\subsubsection{Impact Test Specimen}

Impact test specimens were according to ASTM D610 standard. The photographic view of specimen is shown in the figure 3. The dimensions of the specimen are $63.5 \mathrm{~mm}$ length, $12.7 \mathrm{~mm}$ width and $10 \mathrm{~mm}$ thickness.

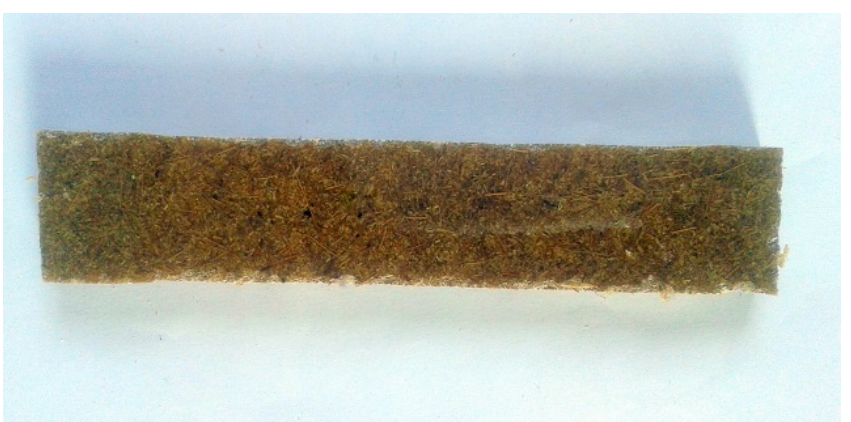

Fig 3: Impact test specimen as per the ASTM standards

\subsubsection{Hardness Test Specimen}

Hardness test specimens were prepared according to ASTM D785 standard. The photographic view of specimen is shown in figure 4 . The dimensions of the specimen are $10 \mathrm{~mm}$ length, $10 \mathrm{~mm}$ width and $8 \mathrm{~mm}$ thickness.

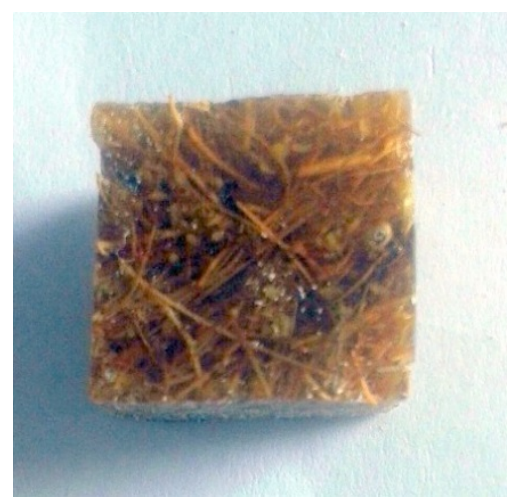

Fig 4: Hardness test specimen as per the ASTM standards

\subsection{Water Absorption Test}

The specimen immersed in water to conduct the moisture absorption test is shown in figure 5

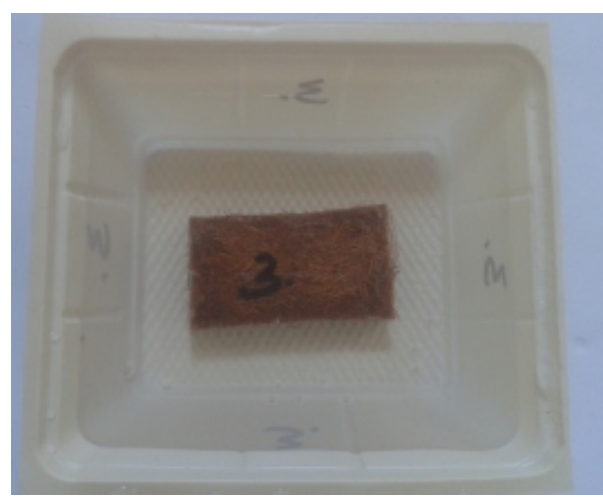

Fig 5: Moisture absorption test Set-Up
After the conducting moisture absorption test the behavior of the specimens shown in the figure 6 .

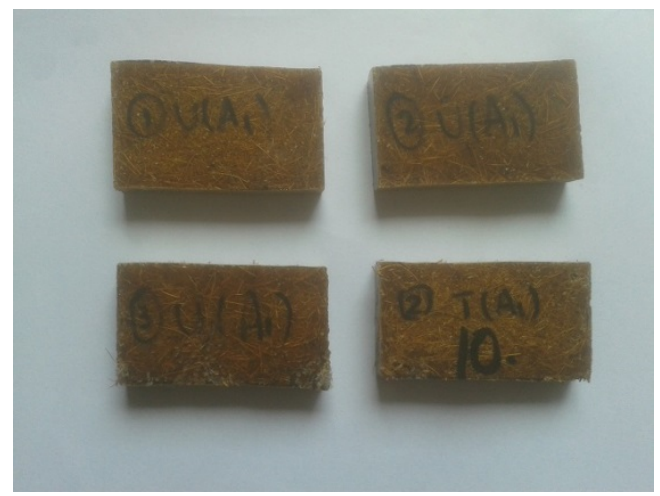

Fig 6: Moisture absorption tested specimens

\section{RESULTS AND DISCUSSION}

\subsection{Impact Strength of Composites}

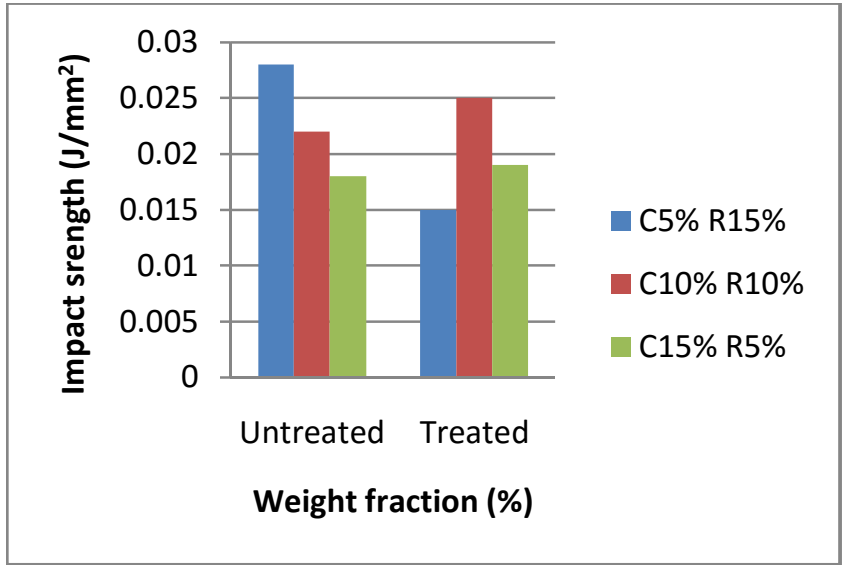

Chart 1. Comparison of impact strength property of the untreated and treated natural composites

The comparison strength of three combinations of natural composites both untreated and treated is shown in chart 1 . From the above graph it is observed that the untreated specimen which having higher rice husk content exhibits higher impact strength as compared to treated specimen. This may due to sufficient filler content present in the composite leads to strong interfacial bonding between reinforcement and matrix [5].

\subsection{Hardness Of Composites}

From the chart 2 it can be observed that the hardness value increases with increase in filler content in the composite. In this, the untreated specimen having more rice husk content exhibits the higher hardness value. This may be due to high filler content present in the composites that makes matrix harder which leads to reduction in the elasticity of composites. 


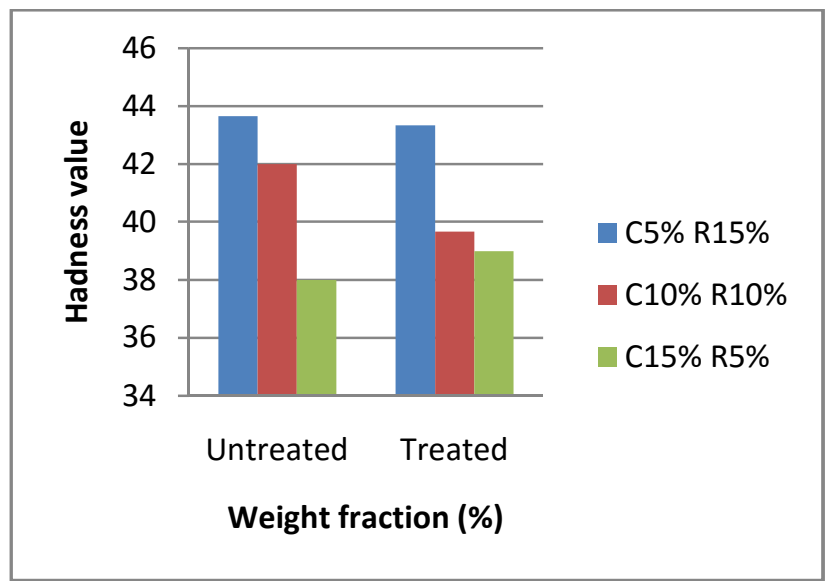

Chart 2.Comparison of Hardness value of the untreated and treated of natural composites

The $15 \%$ fiber content composite has shown a lower trend in hardness. Because there will be higher fiber to fiber contact which leads to poor interfacial bonding between the fiber and the matrix. Due to this poor interfacial bonding effective load transfer may not take place and leads to quick failure.

\subsection{MOISTURE ABSORPTION TEST}

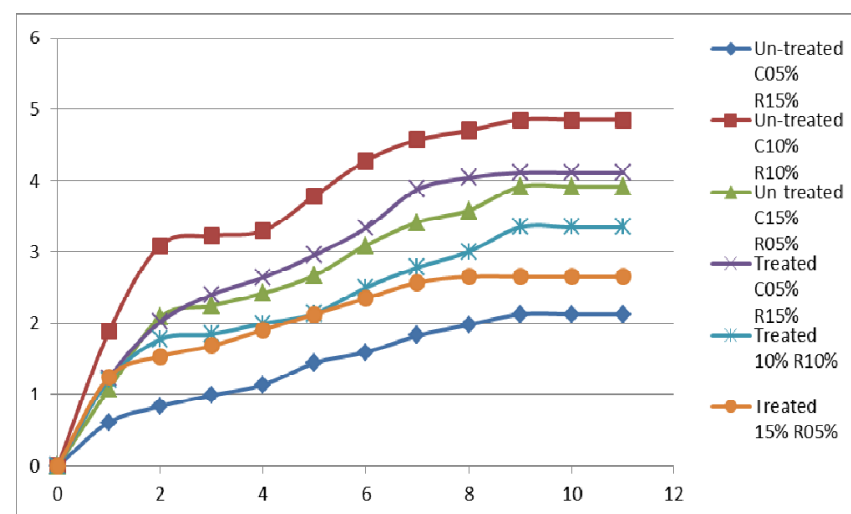

Chart -3:Comparison of moisture absorption property of untreated and treated coir fiber in distil water

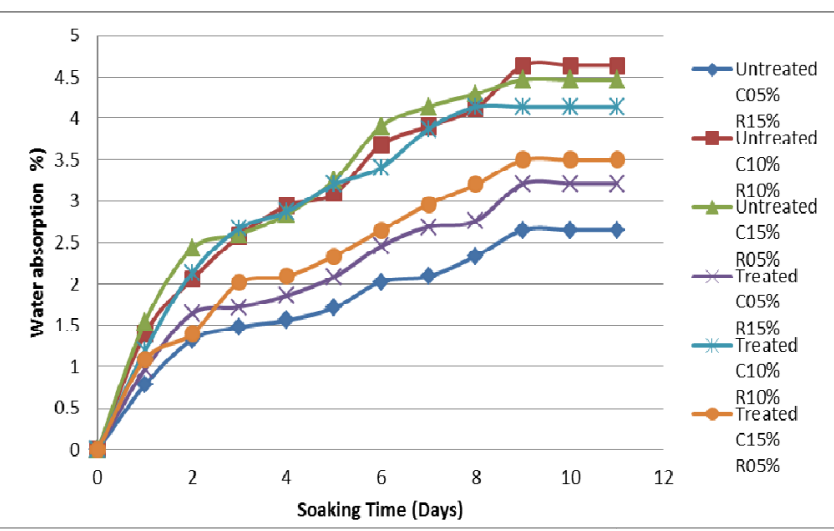

Chart -4 Comparison of moisture absorption property of untreated and treated coir fiber in river water

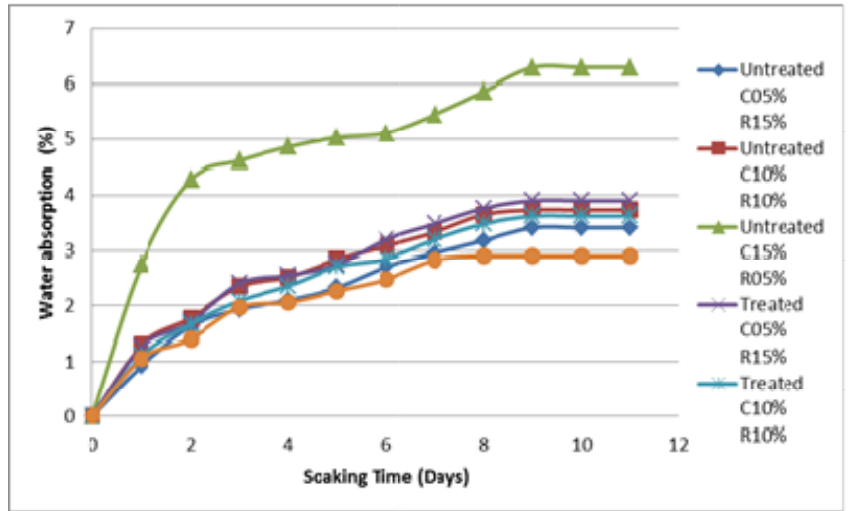

Chart -5: Comparison of moisture absorption property of untreated and treated coir fiber in bore well water

Chart 3, 4and 5 shows moisture absorption test results for distilled water river water and bore well water respectively. From the plotted graphs it can be observed that the amount of moisture in the composite increases with time and later leveled off at longer period, which is an indication of saturation.

From the chart 3,4 and 5 it is observed that chemically treated coir fiber with untreated rice husk powder composites absorbs less water as compared to untreated fiber with untreated rice husk powder composites. This is due to the change in surface tropology of the fiber due to chemical treatment. The chemical treatments had removed most of hemicelluloses and lignin and thus coir fiber become more hydrophobic and the composite with treated fiber absorbs less water.

\section{CONCLUSIONS}

- The Un-treated composite specimen with the combination of Coir $05 \%$ Rice husk powder $15 \%$ composition exhibits higher impact strength as compared to other untreated and treated compositions.

- The Un-treated composite specimen with the combination of Coir $05 \%$ Rice husk $15 \%$ composition exhibits higher hardness value as compared other compositions.

- The treated composites exhibits higher water absorption resistance as compared to untreated composites.

- Finally it is concluded that untreated composite specimens exhibit better mechanical properties as compared to fiber treated composites, but fiber treated composites exhibits better water absorption resistance.

\section{REFERENCES}

[1]. P.K. Mallick., "Fiber reinforced composites": Materials, Manufacturing, and Design third edition, 2007.

[2]. P A Sreekumar., "Matrices for natural-fiber reinforced composites". (C) 2008

[3]. Autar K Kawa., "Mechanics of composite Materials". Second edition (C) 2006

[4]. S.A. Sayed Azuan., "Effect of volume fraction on tensile properties of rice husk reinforced polyester 
composites": Journal of applied research, 9(4): 25612565, ISSN 1819-544X, 2013.

[5]. Omar Faruk, Andrzej K. Bledzki, Hans-Peter Fink, MohiniSain., "Bicomposites reinforced with natural fibers: 2000-2010": progress in polymer science 37(2012)1552-1596

[6]. Mr. Biren J Saradava, Prof. Nikunj V. Rachchh, Dr. R. K. Misra, Dr. D. G. Roychowdhary., "Mechanical characterization of coir fiber reinforced polymer composite using red mud as filler": Journal of information, knowledge and research in mechanical engineering, Volume - 02, ISSUE - 02, ISSN 0975668X, Nov 2013.

[7]. M.Sakthivel, S. Ramesh., "Mechanical properties of natural fiber (Banana, Coir ,Sisal) polymer composites": SCIENCE PARK ISSN: 2321-8045 ISSN 2321-8045

[8]. F.Z. Arrakhiz, M.E. Achaby, A.C. Kakou., "Mechanical properties of high density polyethylene reinforced with chemically modified coir fibers": Impact of chemical treatments: Materials and design 37(2012)379-383, 2012.

[9]. Omar Faruk, Andrzej K. Bledzki, Hans-Peter Fink, MohiniSain., "Bicomposites reinforced with natural fibers: 2000-2010": progress in polymer science 37(2012)1552-1596, 2012.

[10]. U.S. Bongarde, V.D. Shinde., "Review on natural fiber reinforcement polymer composites": International ournal of engineering science and innovative technology (IJESIT) volume 3, issue 2, ISSN: 23195967, 2014

[11]. Dhanalakshmi, Sampathkumar, RamadeviPunyamurthy, BasavarajuBennihalli and SrinivasaChikkolVenkateshappa., "Efect of esterification on moisture absorption of single areca fiber", International Journal Of Agricalture Sciences Issn: 0975-3710 and E- Issn: 0975-9107, Volume 4, Issue 4, pp.227-229, 2012

[12]. Tran Huu Nam, Shinji Ogihara, Nguyen Huy Tung, Stoshi Kobayashi., " Effect of alkali treatment on interfacial and mechanical properties of coir fiber reinforced poly(butylene succinate) biodegradable composites": Composites: part B 42(2011)1648-1656, 2011.

[13]. Md. Rezaur Rahman, Md. Nazrul Islam, Md. MonimulHuque, SininHamdan and $\mathrm{Abu}$ Saleh Ahmed., "Effect of chemical treatment on rice husk (RH) reinforced polyethylene (PE) composites":Bioresources 5(2), 854-869, 2010.

[14]. YaningZang, A.E. Ghaly,Bingxi Li., "Physical properties of rice residues as affected by variety and climatic and cultivation conditions in three contents" American Journal of Applied Sciences, 9(11), 17571768, ISSN 1549-9239, 2012.

\section{BIOGRAPHIES}

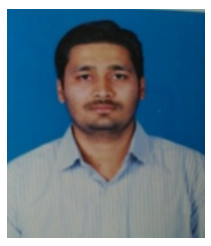

Abhishek T.H.M. has obtained his Bachelor's Degree in Mechanical engineering from S.K.S.V.M.A. College of Engineering, Laxmeshwar and Master's Degree in Production Engineering and Systems Technology from University B.D.T. College of Engineering, Davangere.

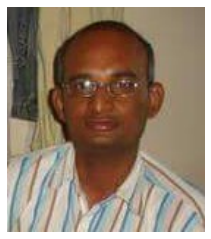

G.K. Mruthyunjaya Gouda, HOD, Department of Mechanical Engineering, Impact college of Engineering and applied science, Bengaluru. He has obtained his Bachelor's degree in Mechanical Engineering from B.L.D.E.A's college of Engineering, Vijayapura and Master's Degree in Production Engineering and Systems Technology from University B.D.T. College of Engineering, Davangere 